\title{
HIV positive Children at AIDS dissidents families - how to help
}

\author{
Nataliia Moisieieva, Childhood - without AIDS, Ukraine
}

In Ukraine HIV - positive children have free access for ART, but among barriers to pediatric HIV care one of the most common is non - adherence to treatment of parents.

Last year National Children AIDS Clinic faces postponed diagnostic and ARV treatment on 6 children because of parents were AIDS dissidents. All children have had $3^{\text {ed }}$ ore $4^{\text {th }}$ clinical stages of HIV disease with severe cognitive problems, different opportunistic infections and risk of death. Generally, in Ukraine there were 11 cases of children's deaths connected with parents non - adherence for ART in 2017.

All this children were infected with mother - to - child transmission. During pregnancy all mothers received HIV counselling, three of them refused HIV testing, and five of them refused prevention treatment ART. Parents refused Cotrimoxazole as prophylaxis against opportunistic infections, ART, TB treatment and prevention.

Clinical case. Child, male, 2,5 years all, was born to mother, who have not received prevention ART during pregnancy. During delivery, lower denied to provide HIV test of umbilical blood, and ATRT for children was nor prescribed. Mother was died 3 month ago with TB. During examination: child has $20 \%$ weight deficit, during last 3 months he lost skills (walking and speaking), $C D=$ $64 \mathrm{cell} / \mathrm{ml}$; VL $=2500000$ copies $/ \mathrm{ml}$. Child father denies ART and TB treatment. Healthcare workers have no instruments to provide treatment for child in such cases.
Ukrainian Health care providers need legal support to defend children health and life at families of AISD- dissidents in cases when children are under the risk of death and harm for health. Social workers, lawyers have to support children and replace them into foster families.

what treatment and care AIDS - dissedents

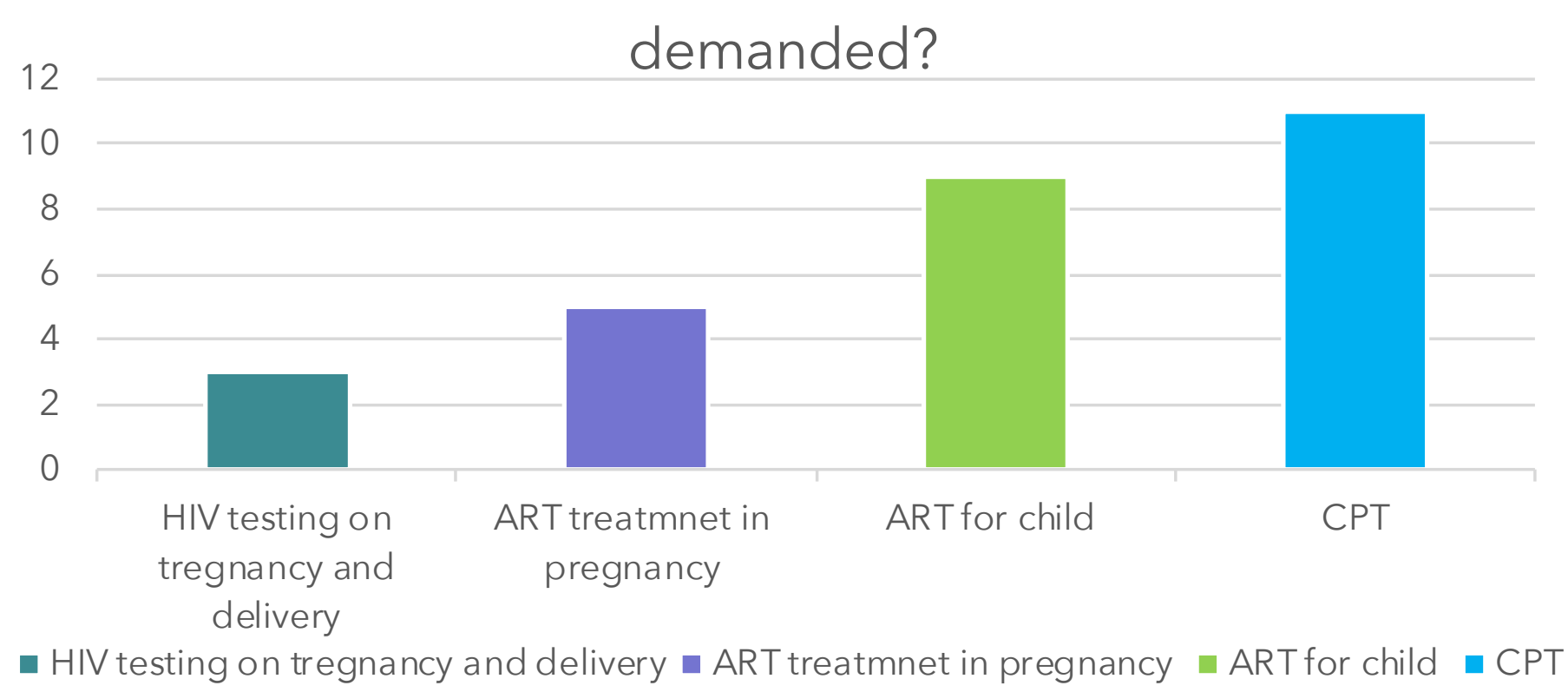

